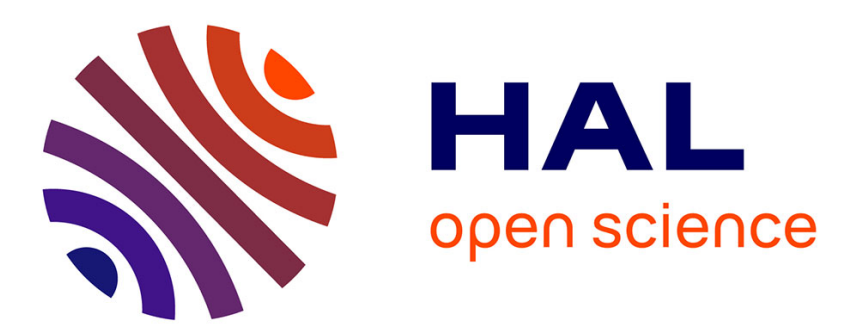

\title{
Actuality Entailments: When the Modality is in the Presupposition
}

\author{
Alda Mari
}

\section{To cite this version:}

Alda Mari. Actuality Entailments: When the Modality is in the Presupposition. Lecture Notes In Computer Science, pp.191-210, 2016. ijn_02162129

\section{HAL Id: ijn_02162129 \\ https://hal.science/ijn_02162129}

Submitted on 21 Jun 2019

HAL is a multi-disciplinary open access archive for the deposit and dissemination of scientific research documents, whether they are published or not. The documents may come from teaching and research institutions in France or abroad, or from public or private research centers.
L'archive ouverte pluridisciplinaire HAL, est destinée au dépôt et à la diffusion de documents scientifiques de niveau recherche, publiés ou non, émanant des établissements d'enseignement et de recherche français ou étrangers, des laboratoires publics ou privés. 


\title{
Actuality entailments: when the modality is in the presupposition
}

\author{
Alda Mari \\ Pogodalla S., Retoré C. (eds) Logical Aspects of \\ Computational Linguistics. Lecture Notes in Computer \\ Institut Jean Nicod, CNRS/ENS/EHESS \\ Science, vol 10054. Springer, Berlin, Heidelberg, pp. \\ 191-210.
}

Mari A. (2016) Actuality Entailments: When the Modality is in the Presupposition. In: Amblard M., de Groote P.,

Fortheoming in Lecture Notes in Computer Science, Springer Verlag.

\begin{abstract}
In natural language, modals are not implicative. However, when the modality is combined with the perfective, it shows an implicative (or factive) behavior. This phenomenon is called 'actuality entailment'. We show that actualitgexentailments arise with goal-oriented modality only and endorse Belnap's view of that goal-oriented modals use historical accessibility with a fixed past and an open future. This modal-theoretic assumption allows us to spell out the precise modaltemporal configuration in which the actuality entailment arises and our predictions are borne out by the data, cross-linguistically. We also show that, when any assumption about the identity of worlds at branching point is leveled - which appears to be the case with generic deontic and opportunity modals -, the actuality entailments disappear. We also predict that the entailment disappears with prospectivity. Finally, we argue that modal sentences giving rise to actuality entailments are informative, insofar as the contribution of the modality survives as a presupposition that the modal base is non-homogeneous.
\end{abstract}

Key-words: Modality · Presupposition · Actuality Entailments · Goal; Intentionality $\cdot$ Implicative Verbs.

\section{Introduction}

Modals in natural language are not implicative. ${ }^{1}$ This is observed for existential (e.g 'might') and universal (e.g 'must') modals, both epistemic ((1-b), (1-d)) and deontic ((1-a), (1-c)).

(1) a. He is allowed to go to school. $\not \rightarrow$ He goes to school.

b. He might be sick. $\rightarrow$ He is sick.

c. He must go to school. $\not \rightarrow$ He goes to school.

d. It must be raining. $\nrightarrow \rightarrow$ It rains.

\footnotetext{
${ }^{1}$ Special thanks to Anastasia Giannakidou for the long discussions on several aspects of this work. I am also grateful to Chris Kennedy, Itamar Francez, Malte Willer, Guillaume Thomas and the three anonymous reviewers for comments and suggestions. This research was funded by ANR-10- LABX-0087 IEC and ANR-10-IDEX-0001-02 PSL. This paper was written during my stay at the University of Chicago 2014-2016. We also gratefully thank the CNRS-SMI 2015.
} 
However, as observed by [4], in some modal-temporal combinations the modality is implicative. In the specific context of the study of modality in interaction with time this phenomenon has been called actuality entailment [4] and maintain here this terminology.

Actuality entailments were immediately observed as arising when the modal is in the perfective. Bhatt's observation has been replicated across a variety of languages (see, e.g. for French, [20], [32], [23]; for Italian, [31]; for Greek [18] a.o). ${ }^{2}$ In French, the language studied in this paper, the actuality entailment arises with the passé composé.

$$
\begin{aligned}
& \text { Jean a pu prendre le train, \#mais il ne l'a pas pris. } \\
& \text { John has can.pp take the train, \#but he not that-has taken. } \\
& \text { Intended: 'John managed to move the table, \#but he did not do it.' }
\end{aligned}
$$

The imparfait cancels the actuality entailment in French (a contrario, see [18], [9]).

(3) John pouvait prendre le train, mais il ne l'a pas pris. John can.impf take the train, but he not that-has taken. 'John could have taken the train, but he did not take it.'

Bhatt (ibid.) proposes that the modal is ambiguous and that in addition to a non-implicative $\operatorname{can}_{1}$, there is an implicative $\operatorname{can}_{2}$ that behaves just like the implicative manage to. Bhatt also argues that the imperfective conveys generic information, which prevents the actuality entailment from arising. [32] observe that imperfectivity cannot cancel the implication with implicative verbs like 'arriver à' (manage to) and thus that the modality cannot be implicative to begin with.

With the aim to provide a unified theory for modals, theoreticians have built on the assumption that modals in natural language are non-implicative. The debate has been very active since [4] and, most prominently, [20], and various proposals have sought to maintain the non-implicativity of the modals. ${ }^{4}$

The major challenge faced by any theory of actuality entailments is distinguishing between modal statements giving rise to the entailment ((4-a) and (4-b)) and non-modal statements (4-c). In this paper, we focus on existential modals, since the entailment of actuality is unexpected under any approach of possibility modals.

$$
\begin{aligned}
& \text { a. Jean a pu prendre le train. } \\
& \text { John has can.pp take the train. } \\
& \text { 'John managed to take the train. }
\end{aligned}
$$

\footnotetext{
${ }^{2}$ Several authors do not subscribe to an aspectual analysis, though, and some of them argue that aspect does not play a role at all (see e.g., [18]).

${ }^{3}$ In the glosses pp is for 'past participle', and impf for 'imperfective'.

${ }^{4}$ For a discussion of available accounts, see a draft version of this paper at http: //ling.auf.net/lingbuzz/002634.
} 
b. Jean a dû prendre le train.

John has must.pp take the train.

'John had to take the train (and he took it).

c. Jean a pris le train.

John has taken the train.

'John took the train.'

All existing approaches ([20], [32], [23]) derive the entailment via complex calculi, begging the question of why the speaker would choose such a complex interpretation to ultimately entail $p$, rather than asserting a non modal statement to begin with.

Likewise, since $\nabla p$ is asymmetrically entailed by $p$, the question should be posed of how the Gricean Maxim of Quality would be respected in the case where the modal is implicative.

On the assumption that truth of modal statements is evaluated with respect to a set of possible worlds, the modal base, we propose that the following axiom (informally, for now), holds for all modals in natural language (see [13], [8], [31] and $[16])^{5}$.

(5) Non-Homogeneity Axiom of modals - [16]

Modal bases triggered by a modal are non-homogeneous, i.e. they contain $p$ and non- $p$ worlds.

In order to disentangle modal from non-modal statements in the passé composé, we need to show how the non-homogeneity conditions of the modals is fulfilled when the actuality entailment arises.

Our claim is that this condition survives as a presuppositions of those sentences in which the modal gives rise to the entailment.

The paper is structured as follows. We discuss new data in section 2, present the analysis in section 3 and discuss remaining questions in section 4 .

\section{Goals and Expectations: New Facts}

With [20] and [5], we observe that the actuality entailment arises with abilitative (6), teleological (7) and non-generic ${ }^{6}$ deontic (8) modality in the passé composé.

(6) Jean a pu déplacer la table, \#mais il ne l'a pas John has can.pp move the table, \#but he not that-has déplacée. move.pp.fem. 'John managed to move the table, \#but he did not move it.'

(7) Jean a pu prendre le train, \#mais il ne l'a pas pris. John has can.pp take the train, \#but he not that-has taken.

\footnotetext{
${ }^{5}$ For more discussion on the notion of non-homogeneity, see also [14], [17].

${ }^{6}$ For generic deontic modality and the distinction between generic and goal-oriented deontic modality, see [31].
} 
'John managed to take the train, \#but he did not take it.'

Jean a pu rentrer à la piscine grâce au nouveau John has can.pp enter to the swimming-pool thanks to-the new règlement, \#mais il n'est pas rentré. rules, \#but he not-is enter.pp.masc.

'John could enter (and did enter) to the swimming-pool thanks to the new rules, \#but he did not enter.'

Most importantly, common to the cases in which the entailment arises is the fact that the entity denoted by the subject ${ }^{7}$ pursues a goal. None of the sentences above can be continued by 'but he did not want it.' (note that 'manage to' does not trigger this intentionality component). For space limitations, we observe this generalization only for $(6)$.

(9) Jean a pu déplacer la table, \#mais il ne voulait pas la déplacer.

John managed to move the table, but he did not want to move it.

Note also, that (10) is felicitous only if John has the intention of being liked (see [28], [29]).

John a pu plaîre.

John has can.pp be liked.

'John managed to being liked.'

This intentionality feature is absent from the meaning of the implicative 'arriver à' ('manage to'). When we contrast past modals triggering the actuality entailment with the implicative verb arriver à ('manage to'), we see that there is intentionality with the modal sentence but not with arriver $\grave{a}$. The English sentence 'He managed to be dumped' can be translated in two different ways (11-a) and (11-b).

a. Jean est arrivé à se faire quitter. (no intentionality)

Gianni is arrive.pp to refl make dump.

b. Jean a pu se faire quitter. (intentionality)

Gianni has can.pp refl make dump.

'He managed to be dumped'.

In (11-a), John plays the role of the victim who has been dumped by his girlfriend. In (11-b), his girlfriend is the victim, as the sentence conveys that John had the goal of being dumped.

This leads us consider the abilitative, teleological and deontic modalities in (6), (7) and (8), as instances of goal-oriented modality. Portner (2009) uses the term 'dynamic modality' to subsume these three types of goal-oriented modals and dedicates the term 'goal-oriented modal' for one subtype of dynamic modality. The term goal-oriented modality which we maintain here will help us recall

\footnotetext{
${ }^{7}$ It can also be a contextually relevant entity, like the captain of a boat in 'Le navire a pu rentrer au port' (The boat managed to enter into the harbor).
} 
that across the instances of goal-oriented modality, agents and entities have goals.

Another key factor enhancing the emergence of the entailment (gone unnoticed in the literature - see [28] though) is that the modal giving rise to the entailment can only be used only if the participants in the conversation expect that the goal cannot be fulfilled. This expectation, as we now show, is a presupposition.

Consider the following scenario. As is well-known, Usain Bolt is the fastest runner in the world, who can run 100 meters in 9.58 seconds.

Usain Bolt a pu battre le record du monde des 100

Usain Bolt has can.pp break the record of-the world of-the 100 mètres grâce à son entranement.

meters thanks to his training.

'Usain bolt managed to break the 100-meter world record thanks to his training.'

Breaking the world record is never granted, and the possibility that even Usain Bolt does not break it is open at a time prior to the race. The sentence is felicitous. Sentence (14), instead, is infelicitous in Context 1 and felicitous in Context 2 described in (13).

(13) a. Context 1 : Usain Bolt is in his best shape and at the climax of his career.

b. Context 2: Usain Bolt is recovering from a long cold and is far from his highest standards.

(\#)Usain Bolt a pu courir 100 mètres en 15 secondes

Usain Bolt has can.pp run 100 meters in 15 seconds

aujourd'hui.

today.

'Usain Bolt managed to run 100 meters in 15 seconds today.'

Consider context (13-a), in which sentence (14) is infelicitous. Since Usain Bolt can run 100 meters in 9.58 seconds, it is taken for granted that, in his best shape, he can run 100 meters in fifteen seconds, and the possibility that he does not run 100 meters in fifteen seconds was not even considered.

Sentence (14) is instead felicitous in context 2 (13-b), where Usain Bolt is recovering from a very bad cold. In this context, running 100 meters in fifteen seconds is not granted; the possibility of $\neg p$ was expected to be realized.

The un-modalized sentence (15) is felicitous in both contexts (13-a) and (13-b), instead. It does not require that $\neg p$ was expected.

(15) Usain Bolt a couru 100 mètres en 15 secondes.

Usain Bolt has run.pp 100 meters in 15 seconds.

'Usain Bolt has run 100 meters in 15 seconds.' 
Importantly, such expectation triggered by past goal-oriented modals must be part of the utterance context prior to utterance, and encodes what the participants take for granted (on this property of presuppositions, see e.g. [38], [40]), as the 'wait a minute' test (designed to detect presuppositions - [11]) shows. Consider the following scenario. My mother has to take the train to her home in the south of the country. She generally goes there every weekend, and she phones my husband or me to tell us that she has arrived. She generally phones me on Saturday. My husband comes home and asks whether she has arrived (see (16)).

$$
\begin{gathered}
\text { Est-ce que ta mère est arrivée? } \\
\text { your mother is arrived? }
\end{gathered}
$$

'Did your mother arrive?

If I reply (17), and my husband is not aware that it was not granted that my mother would take the train, he would be entitled to ask (18).

Oui, elle a pu prendre le train. Yes, she has can.pp take the train. 'Yes, she managed to take the train.'
Attends, il y
avait
un problème?
Wait, it there have.3sg.impf a problem?
'Wait a minute, there was a problem?'

This shows that both participants must know that prior to the time at which $p$ is realized, there was a time $t^{\prime \prime}$ such that $\neg p$ was expected to be realized. If this presupposition is not met, the sentence is infelicitous.

The following family of sentences also reveals that we are dealing with a presuppositions. Again, (19)-(20)-(21) are felicitous only in contexts implying that not running 100 meters in fifteen seconds is expected (Usain Bolt is recovering from a cold - see Context 2 in (13-b)).

$$
\begin{array}{r}
\text { (\#)Est-ce qu' il a pu courir } 100 \text { mètres en } 15 \text { secondes, } \\
\text { He has can.pp run } 100 \text { meters in } 15 \text { seconds, }
\end{array}
$$

aujourd'hui?

today?

'Did he manage to run 100 meters in 15 seconds?'

(\#)Il est possible qu'il ait pu courir 100 mètres en 15

It is possible that-he has.3sg.subj can.pp run 100 meters in 15 secondes.

seconds.

'It is possible that he managed to run 100 meters in 15 seconds'.

(\#)S'il a pu courir 100 mètres en 15 secondes, alors il If-he has can.pp run 100 meters in 15 seconds, then he va bient ôt se remettre.

go.3sg.pres soon refl be-fine. 
'If he managed to run 100 meters in 15 seconds, then he is going to be fine soon.'

In view of these data, we can conclude that the modal contributes meaning by introducing a meaning component conveying 'expectation.'

\section{Analysis}

\subsection{Representing Goal-Oriented Modality}

[2] is the first to propose an analysis of goal-oriented modality within a branching time framework [39]. ${ }^{8}$ We endorse this model theoretical framework for goaloriented modality in French as well. As we show, this choice will allows us to derive a variety of predictions, cross-linguistically.

The Modal-Temporal Skeleton Thomason's world-time model uses $W \times T$ frames. A branching structure is generated. Each branching point determines an equivalence class of worlds with a unique past and present and an open future. A three-place relation $\simeq$ on $T \times W \times W$ is defined such that (i) for all $t \in T, \simeq_{t}$ is an equivalence relation; (ii) for any $w, w^{\prime} \in W$ and $t, t^{\prime} \in T$, if $w^{\prime} \simeq_{t^{\prime}} w$ and $t$ precedes $t^{\prime}$, then $w^{\prime} \simeq_{t} w$ (we use the symbols $\prec$ and $\succ$ for temporal precedence and succession, respectively). In words, $w$ and $w^{\prime}$ are historical alternatives at least up to $t^{\prime}$ and thus differ only, if at all, in what is future to $t^{\prime}$.

Figure 1 depicts two equivalence classes of worlds, determined at $t_{1}$ and $t_{2}$.

a. $\quad w_{0} \simeq_{t_{1}} w_{1} \simeq_{t_{1}} w_{2} \simeq_{t_{1}} w_{3} \simeq_{t_{1}} w_{4}$ (historical alternatives at $t_{1}$ ).

b. $\quad w_{0} \simeq_{t_{2}} w_{2} \simeq_{t_{2}} w_{3}$ (historical alternatives at $t_{2}$ ).

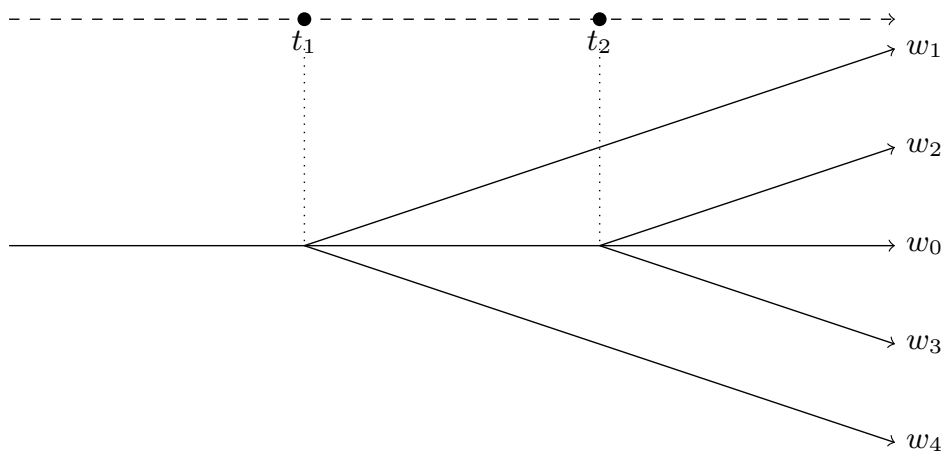

Fig. 1. Equivalence classes of worlds

\footnotetext{
$\overline{8}$ See [8], [25], [30] for discussion of this framework in the linguistic literature.
} 
For any time $t \in T$, on can define the historical alternatives $\mathcal{I}$ as the set of worlds that are identical to the actual world $w_{0}$ at least up to and including $t$.

$$
\mathcal{I}\left(w_{0}\right)(t):=\left\{w \mid w \simeq_{t} w_{0}\right\}
$$

Figure 2 depicts the historical alternatives, determined at time $t$.

$$
\mathcal{I}\left(w_{0}\right)(t)=\left\{w_{1}, w_{2}, w_{0}, w_{3}, w_{4}\right\}
$$

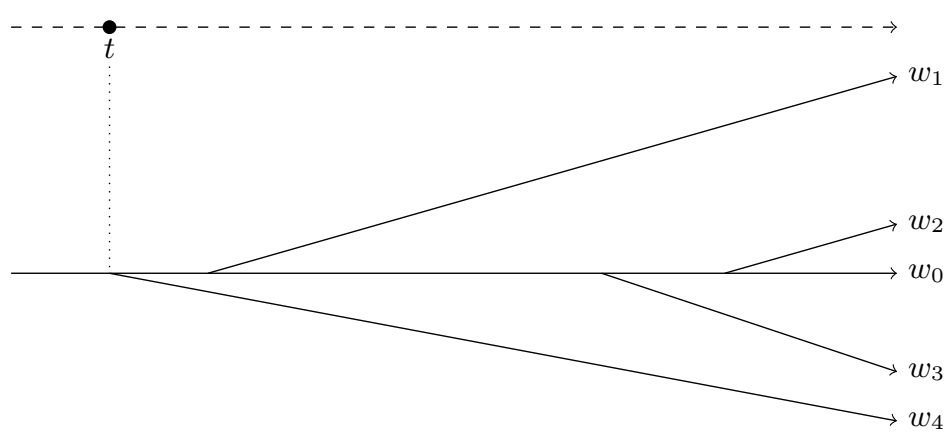

Fig. 2. $\mathcal{I}(t)$

\subsection{Calculating the Asserted Meaning}

Let us work through the compositional semantics of the sentence in (25).

$$
\begin{aligned}
& \text { John a pu [ prendre le train ] } \\
& \text { John managed to take the train. }
\end{aligned}
$$

Following previous analysis, we treat the passé composé as a past. As repeatedly observed, in fact, the actuality entailment arises with the simple past as well [31]. We use $A C C$ for the accessibility relation function, which we further elaborate later in the paper. (From now on, we call the proposition $p$ ('prendre le train' in (25)), the prejacent.)

We assume the decomposition that follows:

$$
\operatorname{PAST}(\mathrm{MOD}(\mathrm{VP}))
$$

As standard, we are going to assume that $s$ is the type for worlds, $i$ the type of times and $t$ the type for truth values.

The meaning of the operators is in $(27)$.

$$
\text { a. } \mathrm{MOD}=\lambda p^{s \rightarrow\langle i \rightarrow t\rangle} \lambda w^{s} \lambda t^{i} \exists w^{\prime}\left[w^{\prime} \in A C C(w)(t) \wedge p\left(w^{\prime}\right)(t)\right]
$$


b. $\quad$ PAST $=\lambda p^{s \rightarrow\langle i \rightarrow t\rangle} \lambda w^{s} \lambda t^{i} \exists t^{\prime}\left[t^{\prime} \prec t \wedge p(w)\left(t^{\prime}\right)\right]$

c. $\mathrm{VP}=\lambda w^{s} \lambda t^{i} p(w)(t)$

Composition.

a. $\operatorname{MOD}(\mathrm{VP})=\lambda w^{s} \lambda t^{s} . \exists w^{\prime}\left[w^{\prime} \in A C C(w)(t) \wedge\left[\lambda w^{s} \lambda t^{i} \cdot p(w)(t)\right]\left(w^{\prime}\right)(t)\right]$ $=$

$\lambda w^{s} \lambda t^{i} . \exists w^{\prime}\left[w^{\prime} \in A C C(w)(t) \wedge p\left(w^{\prime}\right)(t)\right]$

b. $\operatorname{PAST}(\operatorname{MOD}(\mathrm{VP}))=\lambda w^{s} \lambda t^{i} . \exists t^{\prime}\left[t^{\prime} \prec t \wedge\left[\lambda w^{s} \lambda t^{s} . \exists w^{\prime}\left[w^{\prime} \in A C C(w)(t) \wedge\right.\right.\right.$ $\left.\left.\left.p\left(w^{\prime}\right)(t)\right](w)\left(t^{\prime}\right)\right]\right]=$

$\lambda w^{s} \lambda t^{i} . \exists t^{\prime}\left[t^{\prime} \prec t \wedge \exists w^{\prime}\left[w^{\prime} \in A C C(w)\left(t^{\prime}\right) \wedge p\left(w^{\prime}\right)\left(t^{\prime}\right)\right]\right]$

c. $\quad t$ is fixed as $t_{u}$ and $w$ is the world of evaluation

Truth conditions: $\exists t^{\prime}\left[t^{\prime} \prec t_{u} \wedge \exists w^{\prime}\left[w^{\prime} \in A C C(w)\left(t^{\prime}\right) \wedge p\left(w^{\prime}\right)\left(t^{\prime}\right)\right]\right]$

Paraphrase: there is a past time at which there is a world accessible from the world of evaluation, at which $p$ is true (e.g. John takes the train).

Past fixes both the time of evaluation of the modal and of the prejacent (in absence of a tense that fixes the time of evaluation of the prejacent independently of the time of evaluation of the modal, cf. infra). [19] refers to this phenomenon by stating that the tense of the embedded proposition is anaphoric to the higher tense. In other terms, the time of evaluation of the prejacent (the time at which e.g. John takes the train) and the time of the evaluation of the modal (i.e. the time at which the possibility of taking the train occurs) are the same. Note that this is parallel to what happens with implicative verbs. For a sentence 'John managed to take the train' the time at which John takes the train and the time at which John manages to take the train, are the same.

Interpreting the sentence in a branching time framework allows us to explain why the actuality entailment arises when the time $t^{\prime}$ at which the quantificational domain of the modal coincides with the time at which the prejacent is evaluated. In such a past time there is just one world, the actual one. In this configuration this is the only world of evaluation.

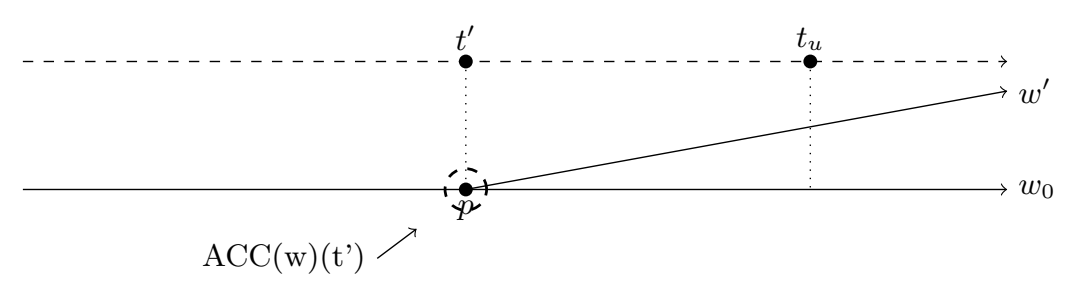

Fig. 3. The domain of quantification of the goal-oriented modality in the past.

Our model theoretic assumptions also allow us to predict that the actuality entailment disappears with prospectivity (PROSP or FUT in the literature, see e.g., [1], [34]), that this to say, in the configuration where the time of evaluation 
of the prejacent follows the time of evaluation of the modality. The actuality entailment, under our hypothesis, does not arise when there is prospectivity because the prejacent lies in possibilities that are not actual, as seen from the time at which the alternatives (the branches) are determined (as we show in section 3.3 this prediction is borne out).

There is no overt mark of prospective aspect in the French language. However, we can demonstrate ex absurdo that if prospective aspect were present when the modal is in the passé composé, we would predict the licit use of forward-shifting temporal adverbs like 'tomorrow'. This type of temporal adverb is incompatible with the modal in the past (29) [23].

$$
\begin{aligned}
& \text { \#Hier il a pu rendre son devoir demain. } \\
& \text { Yesterday he has can.pp return his homework tomorrow. } \\
& \text { '\#Yesterday, Pierre managed to return his homework tomorrow.' }
\end{aligned}
$$

We thus assume that prospectivity is absent when the modal is in the passé composé, and because we do not have a past either (past on the infinitive of the embedded predicate is overt in French), we hold that the time at which the modal and the prejacent are evaluated are the same and are fixed by the higher past operator. In this configuration, the entailment arises.

\subsection{Prospectivity and the Absence of Entailment of Actuality}

The major predictions that we are able to make in adopting the branching time framework, is that the entailment does not arise with prospectivity. This prediction is borne out by cross-linguistic evidence.

Gitksan [34] offers an overt prospective aspect marker dim, which suppresses the actuality entailments.

In Gitksan, modals are lexically restricted with respect to the modal bases they allow: da'akxw is the circumstantial modal.

With dim (which in fact is obligatory with non-epistemic modals) the actuality entailment does not arise.

$$
\begin{aligned}
& \text { da'akxw[-i]-'y } \quad \operatorname{dim} \quad \text { ayee }=\mathrm{hl} \quad \text { bax-'y } \\
& \text { POSSIBILITY[-tra]-1sg.II PROSP go.fast=CN run-1sg.II } \\
& \text { 'I can run fast'. } \\
& \text { Rejected in context: 'You were a fast runner, but you've become perma- } \\
& \text { nently paralyzed.' }
\end{aligned}
$$

In other terms, as predicted, since the modal has future orientation, the actuality entailment does not arise.

The French 'imparfait' features a variety of modal uses that include the counterfactual, as well as the progressive (e.g. [27]). Some (if not all) of these uses have been argued to involve a modal component. [4] and [21] propose that when the modal is in the imperfective, the modal GEN levels the entailment of actuality. 
With [1], for French, we assume that in the counterfactual use of the imperfective, PAST is combined with FUT (here PROSP) - for previous discussion about the counterfactual interpretation of the imperfective, see [3]. (31) is analyzed as in (32) along the lines of $([34])$.

(31) Jean pouvait prendre le train (mais il ne l'a pas pris).

John can.3sg.impf take the train (but he not that-has taken).

'John could take the train (but he did not take it).'

\section{$\operatorname{PAST}(\operatorname{MOD}(\operatorname{PROSP}(\mathrm{VP}))$}

On the assumption that PROSP has the semantics in (33), we obtain the truth-conditions in (34-d) for (31). Let $t_{u}$ be the time of utterance.

$$
\operatorname{PROSP}=\lambda p^{s \rightarrow\langle i \rightarrow t\rangle} \lambda w^{s} \lambda t^{i} \exists t^{\prime \prime}\left[t^{\prime \prime} \in[t, \infty) \wedge p(w)\left(t^{\prime \prime}\right)\right]
$$

Composition.

a. $\operatorname{PROSP}(\mathrm{VP})=\lambda w^{s} \lambda t^{i} \cdot \exists t^{\prime \prime}\left[t^{\prime \prime} \in[t, \infty) \wedge\left[\lambda w^{s} \lambda t^{i} \cdot p(w)(t)\right](w)\left(t^{\prime \prime}\right)\right]$ $=$

$\lambda w^{s} \lambda t^{i} . \exists t^{\prime \prime}\left[t^{\prime \prime} \in[t, \infty) \wedge p(w)\left(t^{\prime \prime}\right)\right]$

b. $\operatorname{MOD}(\operatorname{PROSP}(\mathrm{VP}))=\lambda w^{s} \lambda t^{i} . \exists w^{\prime}\left[w^{\prime} \in A C C(w)(t) \wedge\left[\lambda w^{s} \lambda t^{i} . \exists t^{\prime \prime}\left[t^{\prime \prime} \in\right.\right.\right.$ $\left.\left.\left.[t, \infty) \wedge p(w)\left(t^{\prime \prime}\right)\right]\right]\left(w^{\prime}\right)(t)\right]=$

$\lambda w^{s} \lambda t^{i} . \exists w^{\prime}\left[w^{\prime} \in A C C(w)(t) \wedge \exists t^{\prime \prime}\left[t^{\prime \prime} \in[t, \infty) \wedge p\left(w^{\prime}\right)\left(t^{\prime \prime}\right)\right]\right]$

c. $\operatorname{PAST}(\operatorname{MOD}(\operatorname{PROSP}(\mathrm{VP})))=\lambda w^{s} \lambda t^{i} . \exists t^{\prime}\left[t^{\prime} \prec t \wedge\left[\lambda w^{s} \lambda t^{i} . \exists w^{\prime}\left[w^{\prime} \in\right.\right.\right.$ $\left.\left.\left.A C C(w)(t) \wedge \exists t^{\prime \prime}\left[t^{\prime \prime} \in[t, \infty) \wedge p\left(w^{\prime}\right)\left(t^{\prime \prime}\right)\right]\right]\right](w)\left(t^{\prime}\right)\right]=$

$\lambda w^{s} \lambda t^{i} . \exists t^{\prime}\left[t^{\prime} \prec t \wedge \exists w^{\prime}\left[w^{\prime} \in A C C(w)\left(t^{\prime}\right) \wedge \exists t^{\prime \prime}\left[t^{\prime \prime} \in\left[t^{\prime}, \infty\right) \wedge p\left(w^{\prime}\right)\left(t^{\prime \prime}\right)\right]\right]\right]$

d. $\quad t$ is fixed as $t_{u}$ and $w$ is the world of evaluation.

Truth conditions: $\exists t^{\prime}\left[t^{\prime} \prec t_{u} \wedge \exists w^{\prime}\left[w^{\prime} \in A C C(w)\left(t^{\prime}\right) \wedge \exists t^{\prime \prime}\left[t^{\prime \prime} \in\right.\right.\right.$ $\left.\left.\left.\left[t^{\prime}, \infty\right) \wedge p\left(w^{\prime}\right)\left(t^{\prime \prime}\right)\right]\right]\right]$

Paraphrase: There is a past time $t^{\prime}$ such that there is a world $w^{\prime}$ accessible from the actual world at $t^{\prime}$ such that there is a time $t^{\prime \prime}$ future with respect to $t^{\prime}$ such that $p$ is true at $t^{\prime \prime}$ in $w^{\prime}$.

Since the truth of the prejacent is calculated at a time that follows the time at which the possibilities are projected, given a branching time framework, the actuality entailment does not arises. The prejacent lies in possibilities that are not actual from the perspective of the branching point at which they are projected.

Again, we do not have an overt marking of prospective aspect in French. However, prospectivity is detectable in (35), where forward-shifting temporal adverbs locate the time of the truthiness of the prejacent with the resulting future temporal orientation of the modal.

a. Hier il pouvait rendre son devoir demain. Yesterday he can.3sg.impf return his homework tomorrow. 'Yesterday, Pierre could return his homework tomorrow.' 


\subsection{Accounting for the Contribution of the Modal}

In our account so far, the modal turns out to be trivialized in the assertion, as its domain of quantification contains only one world, the actual one.

We must now implement the contribution of the modal, in order to be able to distinguish between the semantics of bare assertions and modalized assertion in the passé composé. We also elaborate on the constraints on the branches.

Let $t^{\prime \prime}$ be a contextually determined time. We define what follows: ${ }^{9}$

$$
\begin{aligned}
& M B\left(w_{0}\right)\left(t^{\prime \prime}\right)= \\
& \left\{w \in \mathcal{I}\left(w_{0}\right)\left(t^{\prime \prime}\right): \text { a relevant entity has a telos in } w \text { at } t^{\prime \prime}\right\}
\end{aligned}
$$

Note from the outset that having the telos does not imply actualization of the telos. ${ }^{10}$ We posit a condition on the modal space, namely that it is not homogeneous and contains both $p$ and $\neg p$ continuations: $p$ worlds are worlds in which the telos is achieved and $\neg p$ worlds are worlds in which the telos is not achieved.

$$
\begin{aligned}
& \text { Non-homogeneity of the historical modal base (to be revised): } \\
& \exists t^{\prime} \succ t^{\prime \prime}\left(\exists w^{\prime} \in M B\left(w_{0}\right)\left(t^{\prime \prime}\right)\left(p\left(t^{\prime}\right)\left(w^{\prime}\right)\right)\right) \wedge\left(\exists w^{\prime \prime} \in M B\left(w_{0}\right)\left(t^{\prime \prime}\right)\left(\neg p\left(t^{\prime}\right)\left(w^{\prime \prime}\right)\right)\right)
\end{aligned}
$$

Here, the time at which the truthiness of the prejacent is evaluated $\left(t^{\prime}\right)$ follows the time at which the alternatives - including $p$ and $\neg p$ worlds - are projected $\left(t^{\prime \prime}\right)$.

This is not sufficient. As we have shown in the data section, it is not only the case that $\neg p$ was metaphysically possible at a time prior to the realization of $p$ (this is always trivially the case, given a metaphysical space). $\neg p$, instead, was the possibility expected to get realized.

We add ordering sources to restrict the metaphysical space, which, recall, contains worlds in which the subject entity has a certain telos. Recall also that the abilitative, deontic and teleological modal are instances of goal-oriented modality. In our account these flavors of goal-oriented modality are implemented as ordering sources.

Second, in order to implement the notion of expectation, we use a secondary ordering source, which is epistemic ([26]; [36]). We conceive an expectation as an epistemic object: the speaker selects those worlds among the metaphysical accessible ones that better conform to his/her own beliefs [15].

Following [36], we define ordering of worlds and Best worlds as follows.

Ordering of worlds - [36]

For any set of propositions $X$ and any worlds $w, v: w \leqslant_{X} v$ iff for all $p \in X$, if $v \in p$, then $w \in p$.

${ }^{9}$ We use here the aristotelian notion of telos, which includes both goals and tendecies of natural entities, although here we do not discuss the case of this type of entities.

10 The only exceptions to this are natural entities, whose telos (final cause) - e.g., the final cause of the wind is to blow - is necessarily in acto. For space reasons, we do not consider natural entities here. 
For any set of propositions $X$, Best worlds as per $X$.

Best $_{X}:\left\{w^{\prime}: \forall q \in X\left(w^{\prime} \in q\right)\right\}$

$\mathcal{B}, \mathcal{D}, \mathcal{A}$ are, respectively the doxastic, deontic and abilitative ordering sources. These are set of propositions that better conforms to the belief of the speaker (including stereotypicality conditions) $(\mathcal{B})$, the orders and the permissions received $(\mathcal{D})$, and the abilities $\mathcal{A}$ (we will not use $\mathcal{A}$ here).

Let us consider the following example, where permissions (hence a deontic ordering source is considered).

Jean a pu rentrer à la piscine.

John could enter in the swimming pool (and he did enter, in virtue of a permission).

Ordering sources restrict the set of worlds to be taken into consideration. From the entire metaphysical modal base $\mathcal{M}$ (in our case, this is $M B\left(w_{0}\right)\left(t^{\prime \prime}\right)$ ), first the deontic ordering source applies.

$$
\text { Best }_{\mathcal{D}}:\left\{w^{\prime} \in \mathcal{M}: \forall q \in \mathcal{D}\left(w^{\prime} \in q\right)\right\}
$$

The doxastic ordering source, if any, then further restricts Best ${ }_{\mathcal{D}}$.

$$
\text { Best }_{\mathcal{B}}:\left\{w^{\prime} \in \text { Best }_{\mathcal{D}}: \forall q \in \mathcal{B}\left(w^{\prime} \in q\right)\right\}
$$

Let us consider the case of deontically flavored goal-oriented modality (40). ${ }^{11}$ Again, recall that the metaphysical modal space is already restricted to the worlds in which a relevant entity has a telos (namely we are dealing with goal oriented modality), $\mathcal{D}$ restricts the initial domain in which a goal is being pursued. Our final analysis is as follows.

We can now modify the lexical entry for MOD in (27-a), as in (43), where $\mathcal{X}$ is an ordering source.

$$
\mathrm{MOD}=\lambda p^{s \rightarrow\langle i \rightarrow t\rangle} \lambda w^{s} \lambda t^{t} . \exists w^{\prime}\left[w^{\prime} \in \operatorname{Best}_{\mathcal{X}} \wedge p\left(w^{\prime}\right)(t)\right]
$$

a. $\quad$ PAST(MOD(VP) $) \rrbracket$ is defined if and only if there is a contextually determined past time $t^{\prime \prime}$ s.t.

(i) $M B\left(w_{0}\right)\left(t^{\prime \prime}\right)=$

$\left\{w \in \mathcal{I}\left(w_{0}\right)\left(t^{\prime \prime}\right):\right.$ a relevant entity has a telos $p$ in $w$ at $\left.t^{\prime \prime}\right\}$

(ii) $\exists t^{\prime} \succ t^{\prime \prime}\left(\exists w^{\prime} \in \operatorname{Best}_{\mathcal{D}}\left(p\left(t^{\prime}\right)\left(w^{\prime}\right)\right)\right) \wedge$

$\left(\exists w^{\prime \prime} \in \operatorname{Best}_{\mathcal{D}}\left(\neg p\left(t^{\prime}\right)\left(w^{\prime \prime}\right)\right)\right)$

(iii) $\forall w^{\prime \prime} \in \operatorname{Best}_{\mathcal{B}}\left(p\left(t^{\prime}\right)\left(w^{\prime}\right)\right)$

b. If defined, $\llbracket \mathrm{PAST}(\mathrm{MOD}(\mathrm{VP})) \rrbracket=1 \mathrm{iff}$

$t^{\prime}$ defined in (a.-ii.) is such that: $t^{\prime} \prec t_{u}$ such that $\exists w^{\prime}\left[w^{\prime} \in\right.$ Best $_{\mathcal{D}} \wedge$ $\left.p\left(w^{\prime}\right)\left(t^{\prime}\right)\right]$

The presupposition (44-a) can be paraphrased as follows: there is a contextually determined time at which a certain entity has a telos (John intends to go at the

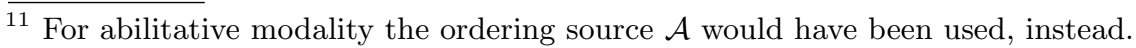


swimming pool). There is a world compatible with the laws such that $p$ is true and a world compatible with the laws such that $p$ is not true, these are the Best $_{\mathcal{D}}$ worlds (note that the time of evaluation of $p$ and $\neg p$ follows the time at which alternatives are projected). In all worlds compatible with the expectations (i.e. in the Best $\left._{\mathcal{B}}\right), p$ is not true.

The sentence asserts (44-b) that at a time $t^{\prime}$ that precedes $t_{u}$ and follows $t^{\prime \prime}$, there is a world compatible with the laws such that $p$ is realized there.

We thus obtain the configuration depicted in figure 4. The actual world is the domain of quantification of the modal DQ, determined at the time $t^{\prime}$.

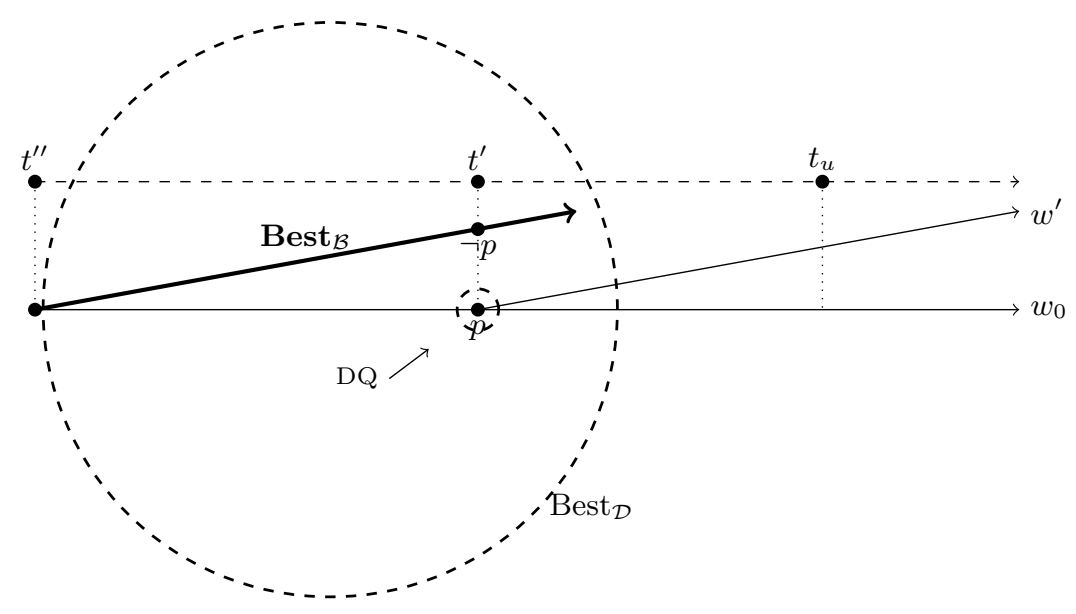

Fig. 4. Domain of quantification $\mathrm{DQ}$, deontic modal base $\mathcal{D}$ and expectations $\mathcal{B}$

Let us add two comments. First we can now provide the final non-homogeneity condition on the deontic flavored goal-oriented modality. This is condition (44-a)(ii). Generalizing for a set of propositions $\mathcal{X} \in\{\mathcal{D}, \mathcal{A}\}$, we obtain:

Non-homogeneity of the modal base for past modals (final).

Let $t^{\prime \prime}$ be a contextually determined past time.

$$
\begin{aligned}
& \exists t_{t^{\prime} \succ t^{\prime \prime}}^{\prime}\left(\exists w^{\prime} \in \operatorname{Best}_{\mathcal{X}} \wedge\left(p\left(t^{\prime}\right)\left(w^{\prime}\right)\right)\right) \wedge \\
& \left(\exists w^{\prime \prime} \in \operatorname{Best}_{\mathcal{X}} \wedge\left(\neg p\left(t^{\prime}\right)\left(w^{\prime \prime}\right)\right)\right)
\end{aligned}
$$

As shown in 4, we can now clearly distinguish between the domain of quantification of the modal from the modal base (this is not a peculiarity of modals giving rise to the entailment, but it is also a well-studied feature of number of modals across languages, see e.g. [41], [16]). The domain of quantification contains just one world, the actual one. In the assertion, the modalized and the nonmodalized statement are equivalent. However, the modal statement contributes meaning in the presupposition. By adding this layer of meaning, the informa- 
tivity of the modal sentence becomes higher than the one of the non-modalized sentence, and the Gricean Quality maxim is fulfilled.

To conclude the discussion, let's consider what happens with negation, considering the case in (46).

Jean n'a pas pu rentrer à la piscine.

John could not enter in the swimming pool (and he did not enter).

(46) states both that (i) the permission is denied and (ii) John did not enter. By negating (44-b), our analysis is as follows.

a. Presupposition. As above.

b. (47) is true iff $\neg t^{\prime}\left(t^{\prime} \prec t_{u}\right)$ such that $\exists w^{\prime} \in \operatorname{Best}_{\mathcal{D}} \wedge\left(p\left(t^{\prime}\right)\left(w^{\prime}\right)\right)$

The condition in (47-b) states that there is no time at which a world compatible with the laws is accessed and $p$ is true. This amounts to stating that the permission is not given. Moreover, since there is just one world, the actual one, we conclude that $p$ is not true there.

Note that the presuppositonal content remains unchanged. There are worlds compatible with the permissions and $p$ is true, and worlds compatible with the permission and in which $p$ is not true. Moreover, the expectation that $p$ would not be true is also maintained. As for the non-homogeneity conditions, it will hold in the metaphysical modal base only (see [8]).

This concludes our discussion of modality giving rise to the actuality entailments. Universal modals will use universal quantification on the entire deontic space, projected at a contextually determined time, preceding the time at which $p$ becomes true.

\section{Further Discussion}

\subsection{Anchoring to Times and Opportunity Reading: the Role of the Adverbs}

We now consider another interpretation of past modals in French that [32] have labeled as the 'opportunity' reading. This reading typically arises when temporal boundaries at which the possibility holds are overtly specified via a temporal adverb. In these cases, the actuality entailment does not arise.

(48) Jean a pu entrer entre 3 heures et 5 heures, mais il n'est John has can.pp enter between 3 hours and 5 hours, but he did pas entré. not enter.

'John had the opportunity to enter between 3 and 5 , but he did not enter.

We are aware of no formal analysis that addresses the opportunity reading. We propose that the opportunity reading of modals is obtained by anchoring 
the modal to the time introduced by the adverb. The opportunity reading is not parametric to teloi; thus, it does not appeal to the historical accessibility relation.

An opportunity can be thought of as a state of affairs that holds over a certain period of time in a certain location. Such states of affairs are indeed what we usually call 'circumstances'. The modal base of the opportunity reading uses circumstantial similarity: it contains those worlds in which the circumstances that obtain in the actual world at the time denoted by the adverb, also obtain, and are such that $p$ is true there.

Leveling the assumption about the identity of worlds and about a settled past and present that the historical accessibility relation introduces allows one to capture the opportunity. In (49), $\mathrm{MB}_{\text {circ }}$ returns the set of worlds circumstantially accessible from $w_{0}$ at $t^{\prime}$ (having leveled the constraint on identity of worlds, these are not identical to $w_{0}$ up to $\left.t^{\prime}\right)$. (49) states that there is at least one accessible world in which $p$ is true at the time provided by the adverb.

$$
\begin{aligned}
& \llbracket(48) \rrbracket=1 \text { iff } \\
& \left.\exists w^{\prime} \in M B_{\text {circ }}\left(w_{0}\right)(\text { between } 3 \text { and } 5 \mathrm{pm})\left(p(\text { between } 3 \text { and } 5 \mathrm{pm})\left(w^{\prime}\right)\right)\right]
\end{aligned}
$$

Without further constraints, the actuality entailment does not obtain as expected.

\subsection{Generic Deontic Modality}

We now consider more closely the difference between addressee-oriented deontic modality and generic deontic modality in relation to actuality entailments.

In French, deontic modality can be both present and past-oriented (pace $[35])$.

$$
\begin{aligned}
& \text { Pour entrer tu dois avoir acheté les billets. } \\
& \text { To get-in you must.2SG have bought the tickets. } \\
& \text { 'You must have bought the tickets to get in.' }
\end{aligned}
$$

$\mathrm{Tu}$ dois être un homme pour pouvoir utiliser ces toilettes.

You must.2SG be a male to can use this restroom.

'You must be a male to use this restroom.'

In our account, the present is settled and represented as a branching point, the time of the utterance. It is predicted under our account that the actuality entailment is obtained in (50) and (51) as well. This conclusion would prove our account wrong, as in (50), it is not entailed that my addressee has bought the tickets, nor that my addressee is a man in (51).

This criticism rests on the unwarranted premise that all instances of deontic modality are instances of goal-oriented modality.

Deontic modality in the present can be interpreted in at least two different ways (see discussion in [36]). First, it can be addressee-oriented. In this case, (50) is felicitous if the addressee still has time to buy the tickets (see [25]) and the speaker is urging him to do so. In other terms, the addressee must be able 
to make $p$ true. In this context, the buying of the tickets lies at a past time $t_{l}$ of a future time, such that $t_{l}$ is in the future of the time of the utterance. The actuality entailment is not obtained because $p$ lies in the future of $t_{u}$, and there is not yet an actual future after $t_{u}$.

Deontic modality can also have a generic interpretation (see [37]). Consider now (50) in the context in which the hearer does not have time to buy the tickets, but the speaker is uttering a general rule, independent of the possible exceptions or correct implementations of the rule. There is no action that the addressee can take to fulfill the rule. We can replicate the observation with (51). Consider a context in which the addressee is a woman. There is no way for the female addressee to change sex instantaneously and become a man. The speaker is thus uttering a rule without expecting the hearer to fulfill it or to have it fulfilled. The same sentence can also be uttered at a male addressee. The addressee can then choose whether or not he wants to use the bathroom. The rule for using the bathroom is provided, but the addressee is not urged to use it.

$$
\begin{aligned}
& \text { a. Male addressee: Est-ce que je peux utiliser ces toilettes? } \\
& \text { 'Can I use this restroom?' } \\
& \text { b. Speaker: Oui, tu dois être un homme pour pouvoir les utiliser. } \\
& \text { 'Yes, you must be a male to use it.' }
\end{aligned}
$$

Here, deontic modality is being used in a generic sentence, where the present tense introduces GEN (see discussion and proposal in [37], ibid). In these cases, the accessibility relation is not historical, and there is not an actual telos being pursued. We would rather use a circumstantial accessibility relation, without any constraints on the identity of worlds (unlike with goal-oriented modality), and a deontic ordering source $(\mathcal{D})$ that ranks as best those worlds in which the rules are obeyed. Given the presence of GEN, one might also want to add normality ordering sources $(\mathcal{N})$. A bouletic ordering source $(\mathcal{B})$ might also be used to take into account the role of personal choices in connection with deontic modality. We do not provide here a full analysis of generic deontic modality. (53) reveal the spirit of it (see [37] for an extended discussion). (D, $\mathcal{N}$ and $\mathcal{B}$ are each a set of propositions).

$$
\begin{aligned}
& \llbracket \operatorname{GEN}\left(\operatorname{MOD}_{\text {deontic }}\right)(p) \rrbracket=1 \text { iff } \\
& \forall w^{\prime} \in \operatorname{Best}_{\mathcal{D}} \cap \operatorname{Best}_{\mathcal{N}} \cap \operatorname{Best}_{\mathcal{B}} \cap\left(M B_{\text {circ }}\left(w_{0}\right)\left(t_{u}\right)\right)\left(p\left(t_{u}\right)\left(w^{\prime}\right)\right)
\end{aligned}
$$

Since we are not assuming historical accessibility here, the actuality entailment does not arise. $^{12}$

\subsection{Past-Oriented Abilitative Modality? A Final Note}

To conclude the discussion about past orientation, we would like to raise a potential final concern about whether there are instances of past-oriented abilitative modality and add a brief note. We have argued that goal-oriented modals (including abilitative modality) are inherently future oriented (the time of evaluation

\footnotetext{
$\overline{12}$ For an overview about the interpretations of GEN, see [33].
} 
of the prejacent is evaluated at a time that follows the time at which the modal base is determined. Note that this is the case in Figure 4). Pouvoir cannot have an abilitative interpretation when past oriented.

Jean peut avoir déplacé la table. (epistemic only)

John can have moved the table.

'John might have move the table.'

Our theory seems thus to deliver a correct prediction.

However, extending it beyond pouvoir and devoir, one can observe that être capable de (be able to) can have past orientation (the time of evaluation of the prejacent is evaluated in the past with respect to the time at which the modal base is determined). Scenario: Mary has been found dead in her bed.

$$
\begin{aligned}
& \text { Jean est capable de l'avoir tuée. } \\
& \text { John is able of her-have killed. } \\
& \text { 'John might have killed her.' }
\end{aligned}
$$

One might want to propose that être capable de is the dedicated expression of abilitative modality. This attempt, however, to confine the coverage of être capable de to abilitative modality is deemed to fail. Several differences exist between the English be able to and its Romance equivalents. In a very recent study of Spanish, [6] and [7] show that one of the peculiarities of ser capaz is its ambiguity between an abilitative and an epistemic interpretation. The new data presented can be straightforwardly duplicated in French - we do not replicate them here for space reasons (see [6] for discussion), and (55) qualify as an epistemic reading of etre capable. Note that, for (55), we have set up a scenario in which the speaker must infer who the murderer is. The use of this type of contexts is the hallmark of epistemic modality (see [36], [12], [16]).

In French, être capable thus shows the same versatility as pouvoir, which, when past oriented, features an epistemic interpretation. As a result, we can conclude that even être capable, just like pouvoir, can have an abilitative interpretation only when future oriented.

\section{Conclusion}

In this paper we have shown that modals in the past give rise to actuality entailments and that this is an unexpected phenomenon given the non-implicative behavior of modals in natural language. We have also show that actuality entailments arise with goal-oriented modality only. We have endorsed the view of [2] that goal-oriented modals use historical accessibility with a fixed past and an open future. These model theoretic assumptions have allowed us to spell out the precise modal-temporal configuration in which the actuality entailment arises and our predictions are borne out by the data, cross-linguistically. We have also shown that, when such an assumption about the identity of worlds at branching point is leveled - which appears to be the case with generic deontic and opportunity modals-, the actuality entailments disappear. 
Finally, we have also shown that modal sentences giving rise to actuality entailments are informative, insofar as the contribution of the modality survives as a presupposition that the modal base is non-homogeneous.

\section{References}

1. Anand, P., Hacquard, V.: The role of the imperfect in Romance counterfactuals. In: M. Prinzhorn, V. Schmitt and S. Zobel (eds.) Proceedings of Sinn und Bedeutung 14, pp. 37-50 (2010)

2. Belnap, N.D.: Backwards and forwards in the modal logic of agency. Philosophy and Phenomenological Research 51, 777-807 (1991)

3. Berthonneau A-M., Kleiber G.: Sur l'imparfait contrefactuel. Travaux de linguistique, 53, 7-65 (2006)

4. Bhatt, R.: Covert Modality in Non-Finite Contexts. PhD thesis, Philadelphia, University of Pennsylvania (1999)

5. Borgonovo, C. and Cummins, S.: Tensed modals. In: Eguren, L., Fernandez Soriano O., (eds.) Coreference, modality, and focus, pp. 1-18. John Benjamins Publishing Company, Amsterdam/Philadelphia (2007).

6. Castroviejo, E., Oltra-Massuet, I.: On capacities and their epistemic extensions. In: Selected Papers from LSRL 42, John Benjamins, Dordrecht (to appear)

7. Castroviejo, E.: What does be capable tell us about capacities? An answer from Romance. Dispositions Workshop. Stuttgart (2015)

8. Condoravdi, C.: Temporal interpretation of modals: Modals for the present and for the past. In: Beaver, D., Kaufmann, S., Clark, B., Casillas, L. (eds.) The Construction of Meaning, pp. 59-88, CSLI, Stanford, CA (2002)

9. Davis, H., Louie, M., Matthewson, L., Paul, I., Reis Silva, A., Peterson, T.: Perfective Aspect and Actuality Entailments: A Cross-Linguistic Approach. In: Proceedings of SULA 5: The Semantics of Under-Represented Languages in the Americas. Amherst, MA: GLSA (2010)

10. Elgesem, D.: The modal logic of agency. Nordic Journal of Philosophical Logic 2, 1-46 (1997)

11. von Fintel, K.: Would you believe it? The king of France is back! Presuppositions and truth-value intuitions. In: Reimer, M., Bezuidenhout, A. (eds) Descriptions and Beyond. Oxford University Press, Oxford (2004)

12. von Fintel, K., Gillies, A.: Must...stay... strong ! Nat. Language Semantics 18, 351-383 (2010)

13. Giannakidou, A.: Affective dependencies. Linguistics and Philosophy 22, 367-421 (1999)

14. Giannakidou, A. and Mari, A.: The future of Greek and Italian : an evidential analysis. Proceedings of Sinn und Bedeutung 17, 255-270 (2013).

15. Giannakidou A., Mari A.: A unified analysis of the future as epistemic modality: the view from Greek and Italian. Ms. University of Chicago and Institut Jean Nicod (2015)

16. Giannakidou A., Mari A.: Epistemic future and epistemic MUST: nonveridicality, evidence, and partial knowledge. In: Blaszack, J. et al. (eds.) Tense, Mood, and Modality : New Perspectives on Old Questions. University of Chicago Press, Chicago (in press)

17. Giannakidou, A. and Mari, A.: Emotive-factive and the puzzle of the subjunctive. Proceeding of CLS 51 2015, 181-195 (2016) 
18. Giannakidou, A., Staraki, E.: Ability, Action and Causation: From Pure Ability to Force. In: Mari, A., Beyssade, C., Del Prete, F. (eds.) Genericity, pp. 250-275. OUP, Oxford (2012)

19. Grano, T.: Control and restructuring at the syntax-semantic interface. PhD University of Chicago (2012)

20. Hacquard, V.: Aspects of Modality. PhD thesis, Cambridge, MA (2006) MIT.

21. Hacquard, V.: On the interaction of aspect and modal auxiliaries. Linguistics and Philosophy 32, 279-315 (2009)

22. Heim, I., Kratzer, A.: Semantics in Generative Grammar. Blackwell Pub, Malden (1998)

23. Homer, V.: French modals and perfective: a case of aspectual coercion. In: Proceedings of WCCFL 28, pp. 106-114 (2010)

24. Kaufmann, S.: Conditional Truth and Future Reference. Journal of Semantics 22.3: 231-280 (2005)

25. Kaufmann, M.: Interpreting Imperatives. Springer, Dordrecht (2012)

26. Kratzer, A.: Modality. In: von Stechow, A., Wunderlich, D. (eds.) Semantics: An International Handbook of Contemporary Research, pp. 639-650. de Gruyter, Berlin (1991)

27. Ippolito, M.: Imperfect Modality. In J. Guéron et J. Lecarme (eds.) The Syntax of Time, pp. 359-387. Cambridge, MA: MIT Press (2004)

28. Mari, A.: Temporal reasoning and Modality. Invited Talk at Temporality : Typology and acquisition, University of Paris VIII, (2010)

29. Mari, A.: Pouvoir au passé composé : effet épistémique et lecture habilitative. In L. de Saussure and A. Rhis (eds.) Etudes de sémantique et de pragmatique Françaises, pp. 67-99. Geneva: Peter Lang (2012)

30. Mari, A.: Each other, asymmetry and reasonable futures. Journal of Semantics 31.2: 209-261 (2014)

31. Mari, A.: Modalités et Temps. Des modèles aux données. Peter Lang AG, Bern (2015)

32. Mari, A., Martin, F.: Tense, abilities and actuality entailment. In: Aloni, M., Dekker, P., et Roelofsen, F., (eds.) Proceedings of the XVI Amsterdam Colloquium, pp.151-156. ITLI, University of Amsterdam, Amsterdam (2007)

33. Mari, A., Beyssade, C., Del Prete, F.: Introduction. In A. Mari, C. Beyssade and F. Del Prete (eds.) Genericity, pp. 1-92. Oxford: Oxford University Press (2012)

34. Matthewson, L.: On the (non)-future orientation of modals. In: Proceedings of Sinn und Bedeutung 16, pp. 431-446 (2012)

35. Niñán, D.: Two puzzles about deontic necessity. In: Gajewski, J., Hacquard, V., Nickel, B., Yalcin, S. (eds.) New Work on Modality, vol. 51 of MIT Working Papers in Linguistics, pp. 149-78. MIT, Cambridge, MA (2005)

36. Portner, P.: Modality. Oxford University Press: Oxford (2009)

37. Saint-Croix, C. and Thomason, R.H.: Chisholm's Paradox and Conditional Oughts. In: Cariani et al. (eds.) DEON 2014, Lecture Notes in Artificial Intelligence, 8554, pp. 192-207 (2014)

38. Schlenker, P.: Local contexts. Semantics and Pragmatics 2: 1-78 (2009)

39. Thomason, R.: Combinations of tense and modality, In: Gabbay, D. M., Guenthner, F. (eds.) Handbook of Philosophical Logic: Extensions of Classical Logic, vol. II, pp. 136-165. Reidel, Dordrecht (1984)

40. Tonhauser, J., Beaver, D., Roberts, C., Simons, M.: Toward a taxonomy of projective content. Language 89(1), 66-109 (2013)

41. Werner, T.: Future and non-future modal sentences. Natural Language Semantics 14: $235-255$ (2006) 